BULLETIN Bulletin hispanique

HISPANIQUE Université Michel de Montaigne Bordeaux

118-1 | 2016

La Guerre Civile espagnole aujourd'hui (1936-2016)

\title{
El aspecto militar
}

estrategias y batallas que marcaron la historia

Fernando Puell de la Villa

\section{CpenEdition}

Journals

Edición electrónica

URL: https://journals.openedition.org/bulletinhispanique/4276

DOI: 10.4000/bulletinhispanique.4276

ISSN: 1775-3821

Editor

Presses universitaires de Bordeaux

Edición impresa

Fecha de publicación: 15 julio 2016

Paginación: 139-156

ISBN: 979-10-300-0058-0

ISSN: 0007-4640

Referencia electrónica

Fernando Puell de la Villa, «El aspecto militar», Bulletin hispanique [En línea], 118-1 | 2016, Publicado el

15 julio 2019, consultado el 21 septiembre 2021. URL: http://journals.openedition.org/

bulletinhispanique/4276 ; DOI: https://doi.org/10.4000/bulletinhispanique.4276 


\title{
El aspecto militar: estrategias y batallas que marcaron la historia
}

\author{
Fernando Puell de la Villa \\ IU Gral. Gutiérrez Mellado, UNED
}

D’un point de vue militaire, la Guerre Civile espagnole s'est déroulée en trois étapes successives. Pour la première, l'objectif principal est la conquête de Madrid, comme l'ont prévu les organisateurs du coup d'État de juillet 1936. Après y avoir échoué, Franco s'empare de la Corniche Cantabrique, dont la perte cause des dommages irréparables à la République. La dernière phase correspond à l'initiative républicaine de déplacer le théâtre des opérations sur la côte méditerranéenne, où la supériorité écrasante des troupes franquistes scelle l'issue du conflit.

Mots-clés: Espagne, Guerre Civile, opérations militaires, armées.

Desde el punto de vista militar, la Guerra Civil española se libró en tres fases sucesivas. En la primera, el principal objetivo fue la conquista de Madrid, conforme a lo previsto por los organizadores del golpe de Estado de julio de 1936. Tras fracasar en ello, Franco logró apoderarse de la cornisa cantábrica, cuya pérdida causó un daño irreparable a la República. La última fase respondió a la iniciativa republicana de trasladar el teatro de operaciones a la vertiente mediterránea, donde la abrumadora superioridad de las tropas franquistas determinó el desenlace de la contienda.

Palabras clave: España, Guerra Civil, operaciones militares, ejércitos.

From a military point of view, the Spanish Civil War had three consecutive phases. Franco's first aim was to conquer Madrid, in accordance with the schedule of the July 1936 coup. After having failed in that, he successfully occupied the Cantabrian ledge, whose loss caused irreparable damages to the Republic. The last phase responded to the Republican initiative of moving the main theatre of operations to the Mediterranean coast, where the pro-Franco army's outmost superiority determined the struggle outcome.

Keywords: Spain, Civil War, military operations, armies. 
T a Guerra Civil española fue la imprevista e inesperada secuela de un golpe $\mathcal{L}$ de estado frustrado, mal planificado por un pequeño grupo de generales cuya carrera militar se había desarrollado en el Protectorado de Marruecos, al que se sumó con entusiasmo aproximadamente un tercio de los militares de alta graduación del Ejército de Tierra, la práctica totalidad de los oficiales jóvenes y casi todos los mandos de la Armada ${ }^{1}$.

La guerra devastó Espańa durante casi mil días, de julio de 1936 a abril de 1939, y terminó con el triunfo de los rebeldes y la instauración de una dictadura acaudillada por el general Francisco Franco ${ }^{2}$. La República Espańola fue abandonada por las democracias occidentales y el único país que acudió en su auxilio fue la Unión Soviética ${ }^{3}$. Franco recibió apoyo diplomático y económico de Hitler y Mussolini, además de su decisiva ayuda militar, y su causa fue bastante bien vista por los gobiernos británico y estadounidense ${ }^{4}$.

El conflicto español tensó las relaciones internacionales en el periodo previo a la Segunda Guerra Mundial y llegó a ser en cierto sentido una pequeña guerra europea en sí misma, que Alemania aprovechó como campo de pruebas para muchas de las tácticas terrestres y aéreas utilizadas después en Europa. La guerra se singularizó por la exaltada y apasionada actitud de los contendientes y por las atrocidades cometidas por ambos bandos en sus respectivas retaguardias.

\section{LA CAPITAL DE ESPAÑA COMO OBJETIVO PRIORITARIO}

La segunda de las instrucciones reservadas del general Mola, director del golpe de Estado, titulada «El objetivo, los medios y los itinerarios» y fechada el 25 de mayo de 1936, establecía: "el Poder hay que conquistarlo en Madrid». Sin embargo, convencido de que allí fracasaría el golpe, decidió apoderarse de la capital mediante cuatro columnas motorizadas procedentes de Valencia, Zaragoza, Burgos y Valladolid, reforzadas por "masas ciudadanas de orden, así como sus milicias, especialmente Falange y Requetés»" 5 .

Sus planes fracasaron estrepitosamente. El general Sanjurjo, consensuado líder de los sublevados, murió al despegar el avión que le traía de su exilio portugués. En Valencia se pudo abortar el golpe; las columnas aragonesas quedaron neutralizadas por el avance de los anarquistas catalanes y valencianos,

1. Fernando Puell de la Villa, "Julio de 1936: ¿un Ejército dividido?», en Jorge Martínez Reverte (coord.), Los militares españoles en la Segunda República, Madrid, Pablo Iglesias, 2012, p. 77-98.

2. Fernando Puell de la Villa y Justo A. Huerta Barajas, Atlas de la Guerra Civil española: antecedentes, operaciones y secuelas militares (1931-1945), Madrid, Síntesis, 2007.

3. Ángel Viñas, La soledad de la República: el abandono de las democracias y el viraje hacia la Unión Soviética, Barcelona, Crítica, 2006.

4. Ángel Viñas, El honor de la República: entre el acoso fascista, la hostilidad británica y la politica de Stalin, Barcelona, Crítica, 2008.

5. Archivo General Militar de Ávila, Fondos de la Guerra Civil, legajo 4, carpeta 8. 
y el gobierno contuvo a las burgalesas y vallisoletanas en la sierra madrileña ${ }^{6}$. Este cúmulo de reveses dio un giro radical al planteamiento inicial, al convertirse las tropas marroquíes en el principal puntal de la sublevación y autoconsiderarse su jefe, el general Franco, como el heredero natural de Sanjurjo, situación sobrevenida que sus conmilitones respaldaron ${ }^{7}$.

Donde los militares alzados en armas triunfaron, el ejército desplazó a las autoridades republicanas y estableció un férreo control sobre la población. Aproximadamente un tercio del territorio quedó en su poder, dividido además en cinco áreas bastante distantes entre sí. La más extensa, dominada por Mola, estaba formada por Galicia, Castilla-León y el norte de Extremadura, más la mitad de Aragón, Navarra, La Rioja y Álava. Una pequeña cuña con centro en Sevilla y sus extremos en Córdoba, Algeciras y Sanlúcar de Barrameda quedó en poder del general Queipo de Llano. En Mallorca e Ibiza también triunfó el golpe, pero no en Menorca. Todas las Canarias fueron controladas por los rebeldes y de allí partió Franco para ponerse al frente del llamado Ejército de África, también sublevado al completo. Las bases navales de Ferrol y San Fernando se sublevaron y sólo la de Cartagena quedó en manos de la República, que también mantuvo casi todos los aeródromos y sus aviones. El golpe se abortó en todas las grandes ciudades, excepto en Sevilla, y en la zona más rica e industrializada del país se mantuvo la legalidad republicana.

Una vez estabilizados los frentes, Franco, tras lograr monopolizar la ayuda de Hitler y Mussolini y convencido de que el gobierno republicano se daría por vencido si se apoderaba de Madrid, se dispuso a conquistarla con el Ejército de África y ese fue su principal objetivo durante ocho meses, de agosto de 1936 a marzo de 1937. Trasladada la Legión y todos los Grupos Regulares Indígenas desde Marruecos a la Península mediante el primer puente aéreo de la historia, sus columnas llegaron a las inmediaciones de Madrid a primeros de noviembre, tras conquistar la mitad occidental de Andalucía, la práctica totalidad de Extremadura, donde se estableció contacto con Mola, y el territorio de Castilla-La Mancha situado al norte del Tajo. Las fuerzas republicanas, integradas mayoritariamente por voluntarios recién reclutados, poco disciplinados y precariamente armados, fueron materialmente barridas por las tropas de Franco.

Sin embargo, aquellos soldados profesionales desconocían totalmente la lucha urbana y no fueron capaces de doblegar la resistencia ofrecida por los miles de milicianos movilizados en defensa de Madrid, a los que se unió poco después un millar de brigadistas internacionales, cuyo tesón y valentía incitaron a los españoles a seguir su ejemplo y aferrarse desesperadamente a sus posiciones ${ }^{8}$.

La ciudad se convirtió en símbolo de la capacidad de resistencia del pueblo español y, a finales de noviembre, tras quince días de lucha, Franco se convenció

6. José Manuel Martínez Bande, La marcha sobre Madrid, Madrid, San Martín, 1982, p. 53-97.

7. Antony Beevor, La Guerra Civil española, Barcelona, Crítica, 2005, p. 215-219.

8. Geoffrey Cox, La defensa de Madrid, Madrid, Oberon, 2005. 
de la imposibilidad de conquistarla mediante ataques frontales y se dispuso a embolsarla por el norte, desde la Casa de Campo a El Pardo para virar después hacia la carretera de Burgos, acción que se saldó con otro fracaso a mediados de enero de $1937^{9}$. En febrero, su empeńo por hacerse con la capital le llevó a intentarlo por el sur y en dirección oeste-este, mediante la también fracasada operación que ha pasado a la historia con el nombre de batalla del Jarama ${ }^{10}$.

Mientras moros y legionarios intentaban embolsar Madrid, tropas fascistas enviadas por Mussolini habían logrado conquistar Málaga con sorprendente facilidad ${ }^{11}$. Mussolini exigió entonces que se las emplease en un escenario más relevante, al considerar que su superior organización y excelente material permitirían resolver la guerra en un par de semanas. Franco, cuyos efectivos habían sufrido un tremendo castigo en el Jarama, se plegó a los deseos de Mussolini y utilizó a los italianos para lanzar un nuevo ataque de envolvimiento de Madrid, en dirección esta vez norte-sur, sobre el eje de la carretera de Barcelona, es decir, les encargó la operación conocida como batalla de Guadalajara, que terminó también en desastre ${ }^{12}$.

Aquellos sucesivos reveses hicieron que Franco aceptase la sugerencia del jefe de Estado Mayor de las futuras Brigadas Navarras, el coronel Vigón, respaldada por el jefe de la Aviación Nacional, el general Kindelán, de renunciar a Madrid y trasladar el eje estratégico principal al adormecido frente vasco, prácticamente inactivo desde que, en el otońo de 1936, las tropas de Mola ocuparon Guipúzcoa y fracasó la ofensiva desencadenada por el aún no militarizado XIV Cuerpo de Ejército republicano contra Vitoria.

\section{La campaña del Norte y las batallas de Brunete y Belchite}

El desenlace de los combates en torno a Madrid supuso el definitivo desplazamiento del teatro de operaciones a la periferia peninsular, iniciándose así la segunda fase de la Guerra Civil, protagonizada por las tropas de Mola. Las brillantes en su planteamiento, aunque fallidas en su ejecución, maniobras de distracción ideadas por el coronel Rojo en La Granja, en Brunete y en Zaragoza para retrotraer la lucha a la zona centro, donde se concentraba la principal masa de maniobra del Ejército Popular, no tuvieron éxito y el teatro de la guerra permanecería muy lejos de la capital hasta el final de la contienda ${ }^{13}$.

A principios de marzo de 1937 se combatía simultáneamente en cuatro frentes. En el norte, Oviedo había caído en manos de Franco, pero su

9. José Manuel Martínez Bande, La lucha en torno a Madrid en el invierno de 1937, Madrid, San Martín, 1984.

10. Luis Díez, La batalla del Jarama, Madrid, Oberon, 2005.

11. Juan A. Ramos, Guerra civil en Málaga 1936-1937, Málaga, Algazara, 2013.

12. John F. Coverdale, «The Battle of Guadalajara, 8-22 March 1937», Journal of Contemporary History, n. ${ }^{9} 9$ (1), January 1974, p. 53-75.

13. José Manuel Martínez Bande, La ofensiva sobre Segovia y la batalla de Brunete, Madrid, Servicio Histórico Militar, 1972. 
comunicación con Galicia era sumamente precaria; Guipúzcoa también, aunque Mola no había logrado penetrar en Vizcaya. En Aragón, los franquistas permanecían a la defensiva, acosados por las columnas procedentes de Cataluña y Valencia. En Andalucía, tras la vertiginosa conquista de Málaga, el frente estaba prácticamente consolidado desde Sevilla a Almería, lo que proporcionaba a Franco una excelente base logística. Y en las inmediaciones de Madrid la situación estaba en tablas.

La frustrada ofensiva sobre Vitoria de diciembre de 1936 había hecho que el lehendakari Aguirre desconfiase de la capacidad de maniobra de sus gudaris, por lo que decidió salvaguardar Vizcaya mediante dos líneas fortificadas, en teoría inexpugnables, según la doctrina imperante por entonces en Francia, que tan inútil sería para detener a Hitler en $1940^{14}$. La primera corría a escasos kilómetros del frente establecido tras apoderarse Mola de Guipúzcoa; más o menos contorneaba el territorio vizcaíno por el sur y por el este y consistía en una sucesión de nidos de ametralladora, unidos por trincheras y alambradas. La segunda, proyectada por el capitán Goicoechea -futuro inventor del TALGO- y llamada popularmente Cinturón de Hierro de Bilbao, era una ristra de búnkeres a unos ocho kilómetros de la ciudad, complementados por observatorios, abrigos subterráneos y caminos cubiertos. Ambas líneas estaban a medio construir cuando empezó la ofensiva, excepto en las zonas más sensibles: las carreteras de Burgos, Vitoria y San Sebastián. Para más inri, Goicoechea cambió de bando y desveló al enemigo los puntos más vulnerables del proyecto ${ }^{15}$.

Para el gobierno republicano, las tropas que guarnecían Vizcaya dependían del general Llano de la Encomienda, pero el lehendakari las puso bajo sus órdenes, lo cual produjo una dualidad en el mando de catastróficas consecuencias. Por ejemplo, pese al interés de Largo Caballero por articularlas en divisiones y brigadas convencionales, Aguirre decidió hacerlo por frentes y sectores, a cargo de militares y civiles adictos al Partido Nacionalista Vasco. Sus efectivos sumaban unos 36.000 hombres, bien pertrechados de armamento, pero con escasez de vehículos blindados. Protegía la costa vasca una pequeña escuadra, pero su mayor debilidad era la falta de aviación ${ }^{16}$.

Por parte franquista, se encomendó la ofensiva a las tropas más fiables del Ejército del Norte: los 28.000 requetés de las Brigadas Navarras. Al iniciarse los combates, se les sumaron 8.000 hombres de la Brigada Flechas Negras, con oficialidad italiana y tropa mayoritariamente española. Si bien podría hablarse de equilibrio de fuerzas en cuanto a efectivos y armamento portátil, el atacante disponía de mucha más artillería y sobre todo de una abrumadora superioridad aérea.

14. Pedro Barruso, La Guerra Civil en Guipúzcoa (julio-septiembre de 1936), San Sebastián, Hiria, 2006.

15. Indalecio Ojanguren, El Cinturón de Hierro, Bilbao, Ikeder, 1996.

16. José Manuel Martínez Bande, La guerra en el Norte (hasta el 31 de marzo de 1937), Madrid, San Martín, 1969. 
El 21 de marzo de 1937, solo tres días después de producirse el descalabro italiano en Guadalajara, Franco ordenó a Mola volcar todo su potencial contra Vizcaya. La idea de maniobra contemplaba dos acciones sucesivas, que, en un exceso de optimismo, se preveía duraran un par de semanas: 1) ruptura de la primera línea fortificada para posicionarse a la altura de Durango, y 2) aproximación y ruptura del Cinturón de Hierro y ocupación de Bilbao ${ }^{17}$.

La primera se inició el 31 de marzo. El Ejército de Euskadi, que esperaba el ataque, se vio sorprendido por las tres horas de intensos bombardeos que precedieron al ataque. Aunque no se pudo impedir la ruptura del frente, sí se logró detener el ataque mucho antes de alcanzar los objetivos previstos. La aviación, aparte de machacar las posiciones de la línea del frente, también arrasó diversos núcleos urbanos a retaguardia. Durango fue despiadadamente bombardeada aquel día, muriendo más de 74 personas y falleciendo en los días sucesivos otras 121. Aguirre pidió desesperadamente aviones al gobierno de Valencia, pero el bloqueo impuesto por el Comité de No Intervención impidió su llegada.

A fines de abril, es decir, dos semanas después de lo previsto para toda la operación, Mola logró posicionarse a unos diez kilómetros del Cinturón de Hierro. La fuerte resistencia encontrada convenció a Franco de que había subestimado al adversario y envió desde Madrid varias unidades de la Legión y de Regulares. El 26 de abril, en el curso de estos combates, la Legión Cóndor, cuyo jefe venía criticando la lentitud de la ofensiva, decidió acelerarla y bombardeó Guernica $^{18}$. La destrucción de la histórica villa, aparte de escandalizar a los europeos, reavivó la moral de combate de los vascos y, aprovechando la crisis gubernamental provocada por los incidentes anarquistas en Barcelona, Aguirre articuló sus tropas en cinco divisiones, que desplegó en torno a Bilbao.

El 1 de mayo, Franco ordenó a Mola iniciar la segunda fase de la ofensiva. Más de un mes se tardó en tomar contacto con las fortificaciones del Cinturón de Hierro y los combates fueron los más sangrientos de la campaña. El 3 de junio, el azar hizo coincidir sendos relevos en el mando de los ejércitos enfrentados en Vizcaya. La muerte de Mola en accidente aéreo, cuando iba a supervisar lo que sucedía en La Granja, puso al general Dávila al frente del Ejército del Norte, y Aguirre cedió a las presiones de Indalecio Prieto, recién nombrado ministro de Defensa Nacional, y se resignó a entregar el mando al general Gámir. Este, al tomar conciencia de la precariedad de sus tropas, propuso sin éxito su repliegue hacia Cantabria.

Dávila disponía de unos 60.000 hombres, abundantísima artillería y clara superioridad aérea. Su idea era romper el Cinturón por su punto más débil, penetrar por el boquete abierto y atacar las fuertes posiciones adyacentes por la retaguardia. El 11 de junio, una enorme masa de 144 piezas de artillería concentró el tiro sobre el punto elegido, mientras 70 aviones lanzaban 100

17. José Manuel Martínez Bande, Vizcaya, Madrid, Servicio Histórico Militar, 1971.

18. Herbert R. Southworth, La destrucción de Guernica: periodismo, diplomacia, propaganda e historia, Granada, Comares, 2013. 
toneladas de bombas. Cuatro días después, los franquistas entraron en Bilbao, abandonado por los republicanos, Dávila se hizo con el corazón minero e industrial de Vizcaya y se situó a las puertas de Cantabria.

A fin de contrarrestar el impacto internacional de la pérdida de Bilbao, Rojo planeó una serie de operaciones en los demás frentes, la principal de las cuales tenía por objeto levantar el cerco de Madrid. Estrechamente supervisada por los asesores soviéticos, se diseńó una ambiciosa maniobra de envolvimiento con las mejores tropas de la República -unos 90.000 hombres, 175 blindados, 217 piezas de artillería y 140 aviones-, que debían atacar en dirección nortesur, desde la carretera de La Coruña hacia Móstoles, y de este a oeste, desde la de Andalucía hacia Alcorcón, para converger en Móstoles y copar las fuerzas que asediaban la capital. La acción, después conocida como batalla de Brunete, se simultanearía con sendas operaciones de distracción en Andalucía, Aragón y Extremadura, al objeto de fijar sus guarniciones ${ }^{19}$.

La principal batalla campal de la guerra, pese a la brillantez de su planteamiento, fue escasamente resolutoria. Aunque relegó definitivamente el frente de Madrid, sólo sirvió para demorar unas semanas la total liquidación del frente norte, éxito franquista que predeterminó el resultado final de la contienda. El plan era perfecto en función del objetivo propuesto y el momento muy oportuno al estar el grueso del Ejército Nacional orientado al Cantábrico. Las tropas que defendían aquel sector no se percataron de los planes enemigos y el 6 de julio los republicanos lograron apoderarse de Brunete. Sin embargo, la acción que debía partir de Vallecas no logró progresar más allá de la carretera de Andalucía.

Franco decidió suspender el ataque contra Cantabria y reforzó el frente de Madrid, logrando frenar el ataque. Los republicanos, embolsados en Brunete y exhaustos tras diez sofocantes jornadas de combate bajo el sol de julio, se establecieron a la defensiva en la línea alcanzada. Cuatro días después, cuando se cumplía el primer aniversario del golpe de estado, los franquistas lanzaron un potente contraataque. Las posiciones republicanas no cedieron, pero los cazas soviéticos se vieron superados por los alemanes. Ambos contendientes, pese al cansancio, la sed y el calor, se aferraron al terreno, sin que ninguno lograra aventajar al contrario. Franco, empeñado en obtener algún triunfo, exigió un último esfuerzo a sus hombres y logró recuperar Brunete. No obstante, los atacantes tampoco daban más de sí y el frente se estabilizó.

Su cansancio interrumpió los combates, pero aquella operación demostró la capacidad de reacción del Ejército Nacional y las muchas carencias del Popular, en particular las de sus mandos. El único logro republicano fue conquistar unos cuantos kilómetros cuadrados en un sector poco relevante del frente madrileño y demorar seis semanas el reinicio de la ofensiva en el Norte.

Al término de la batalla de Brunete, la situación de Cantabria continuaba siendo realmente crítica: las posibilidades de recibir ayuda por tierra eran nulas y la costa estaba bloqueada. Gámir solo disponía de 80.000 hombres, 
escasamente instruidos, mal armados y sin cobertura aérea, a los que Franco quiso impedir que se replegasen a Asturias. A tal efecto, dispuso que sus tropas se apoderaran de Reinosa y se dirigieran directa y rápidamente hacia el mar, dejando embolsada la ciudad de Santander ${ }^{20}$. La operación se realizó con éxito en apenas tres días y el balance de pérdidas republicanas fue desolador, aunque Gámir logró trasladar parte de sus hombres a territorio asturiano.

Ante la imposibilidad de auxiliar a aquel aislado territorio, Rojo planeó otra compleja operación ofensiva en el frente aragonés. La operación, más tarde llamada batalla de Belchite, se encomendó a dos masas de maniobra, emplazadas al norte y al sur del Ebro y apoyadas por 50 blindados, 80 piezas de artillería y 200 aviones, con el objetivo de apoderarse de Zaragoza. La audaz maniobra, teóricamente muy bien concebida, fue la más letal y ambiciosa que planeó Rojo, pero los ejecutantes carecían de la formación e instrucción suficientes para llevarla a cabo con la precisión que exigía su complejidad ${ }^{21}$.

El 24 de agosto comenzó el ataque. La resistencia enemiga hizo fracasar el lanzado al norte del Ebro y la penetración fue muy profunda al sur del río, pero la llegada de refuerzos a Belchite impidió proseguir la marcha hacia Zaragoza. Una vez más, al igual que en Brunete, la aprensión a profundizar por terreno desconocido -el «temor al vacio», que decía Rojo ${ }^{22}$ - desbarató sus planes. Además, los blindados quedaron fuera de combate, acribillados por las escuadrillas alemanas.

Franco decidió no interrumpir la ofensiva en Cantabria y tras ocuparse unos 200 kilómetros cuadrados de terreno baldío, sin valor militar alguno, la acción se centró en Belchite, cuya guarnición rechazó durante dos semanas los reiterados ataques republicanos, obligados a tomar el pueblo casa por casa, piso por piso y habitación por habitación ${ }^{23}$.

Cuando el 7 de septiembre concluyó la refriega, Santander se había perdido y sus conquistadores estaban a punto de penetrar en Asturias, defendida por unos 80.000 hombres, armados con fusiles y ametralladoras, algo de artillería y ni un solo avión. Sólo la tradición revolucionaria de los asturianos, el agreste terreno y la inminente llegada del otoño obraban a su favor. Frente a ellos, unos 110.000 efectivos, con abundancia de armamento y neta superioridad aérea, recibieron orden de avanzar a lo largo la costa y a través de la Cordillera Cantábrica, para converger en Gijón. En unos cuantos días cayeron en sus manos los puertos de la divisoria cantábrica; el frente costero, machacado por la aviación alemana, se desplomó, y Franco logró adueñarse de la mayor parte de Asturias. El drama de la pérdida de la cornisa cantábrica queda suficientemente descrito con decir que, al iniciarse la guerra, la producción hullero-metalúrgica

20. José Manuel Martínez Bande, El final del Frente Norte, Madrid, Servicio Histórico Militar, 1972.

21. José Manuel Martínez Bande, La gran ofensiva sobre Zaragoza, Madrid, San Martín, 1973.

22. Vicente Rojo, España heroica: diez bocetos de la guerra española, Barcelona, Ariel, 1975, p. 111.

23. Amaro Izquierdo, Belchite a sangre y fuego, Barcelona, RBA, 2006. 
en manos de la República era del 71,90 por ciento del total nacional y que, en octubre de 1937, había descendido al 35,40 por ciento ${ }^{24}$.

\section{La batalla de Teruel y la Debacle aragonesa}

A finales de 1937, podía esperarse que la guerra estuviera a punto de acabar, dada la manifiesta inferioridad republicana. No obstante, la lucha se prolongó otros quince meses y, sorprendentemente, el escenario principal se trasladó a Aragón y Cataluña, cosa que no estaba en la mente de Rojo ni en la de Franco. En los combates allí librados en 1938 y 1939, la República fue definitivamente derrotada; en ellos lucharon y murieron miles de hombres en defensa de un ideal; de ellos partió hacia el exilio medio millón de españoles, y allí se alzó Franco con una victoria que marcaría imperecederamente a varias generaciones de españoles.

El afán de Negrín por plantear brillantes operaciones ofensivas con repercusión internacional resultó letal para la República, al ser sucesivamente destruidos sus ejércitos. Si en lugar de ello se hubiera mantenido a la defensiva y planeado una guerra de guerrillas, que obligara a Franco a dispersar sus tropas, tal vez habría dado tiempo a que las potencias occidentales hubiesen socorrido a la República al iniciarse la II Guerra Mundial ${ }^{25}$.

En noviembre de 1937, Franco concentró sus fuerzas en la Alcarria con el objetivo de lanzarlas contra Madrid. Por las mismas fechas, Prieto y Rojo planeaban atacar Extremadura para aislar Andalucía del resto de la zona rebelde. Pero la necesidad de frustrar el ataque sobre Madrid les indujo a apoderarse de Teruel, operación propagandística de escaso valor estratégico. El éxito alcanzado y la obsesión de Franco por no ceder terreno dieron un vuelco a la situación y la contienda pasó a decidirse en el área mediterránea.

Teruel era una pequeña ciudad, unida por un estrecho corredor con su retaguardia; la guarnecían unos 8.000 hombres, poco instruidos y mal armados. Todo ello influyó para que Negrín insistiese en tomar la ciudad a fin de atraer las tropas que se estaban concentrando en la Alcarria. Rojo concibió una operación de alcance limitado para estrangular el citado corredor y establecerse después a la defensiva.

El 14 de diciembre, con niebla y un frío intensísimo, comenzó el ataque. Los republicanos se infiltraron entre las posiciones enemigas y lograron cortar el corredor. El 19 se planeó entrar en la ciudad, a la vista de Indalecio Prieto y un nutrido séquito de periodistas. La aviación alemana malogró el espectáculo y llevó tres días tomarla. Las fotografías de Capa mostrando a los soldados republicanos en las calles de Teruel dieron la vuelta al mundo. Rojo dio la acción por concluida y comenzó a organizar la operación de Extremadura. Pero

24. Javier Rodríguez Muńoz, La Guerra Civil en Asturias, Oviedo, Prensa Asturiana, 2006.

25. Gabriel Cardona, Historia militar de una guerra civil: estrategia y tácticas de la guerra de España, Barcelona, Flor del Viento, 2006, p. 24 y 25. 
la reacción de Franco no se hizo esperar: anuló la ofensiva sobre Madrid y ordenó recuperar Teruel a cualquier coste, con lo que la guerra dio un vuelco definitivo ${ }^{26}$.

La tarea se encomendó al Ejército del Norte, a cuya disposición se pusieron 484 piezas de artillería y la aviación de la Legión Cóndor. El mal tiempo dificultó su traslado y hasta el día 29 no pudo actuar. El 30, muy castigado por la artillería y la aviación, los franquistas rompieron el frente y el día de Nochevieja llegaron a los arrabales de la ciudad. Los republicanos, ante el temor de quedar copados, comenzaron a retirarse, pero Dávila no advirtió que Teruel estaba en sus manos.

Una gran nevada torció el curso de la batalla. Los atacantes fueron diezmados por el frío y sus vehículos quedaron enterrados bajo la nieve. La situación pareció estabilizarse y Rojo volvió a dar por concluida la batalla. Evidentemente, no entraba en sus planes que Franco no estuviera dispuesto a aceptar la derrota, ni que hubiera convertido en cuestión de prestigio la recuperación de la asolada ciudad.

Para doblegar a quienes le habían hecho perder su primera capital de provincia, sometió sus posiciones a un terrible bombardeo. El 17 de enero, toneladas de proyectiles se abatieron sobre los republicanos y Franco creyó poder recuperar Teruel. Los refuerzos llegados lo impidieron, pero no cejó en su intención de desquitarse. Su empeño por recuperar la emblemática ciudad motivó que, a finales de enero, planificase una gran maniobra de envolvimiento, que le abrió el camino hacia el Mediterráneo. La llamada batalla del Alfambra se inició el 5 de febrero. Cañones y aviones machacaron las posiciones republicanas y la caballería penetró diez kilómetros en su territorio. Al día siguiente, la actuación de la aviación se intensificó y los republicanos abandonaron la lucha.

Aquella breve batalla fue uno de los mayores éxitos franquistas, a la vez que un duro revés para los republicanos, quienes, aparte de ceder una extensa franja de terreno, perdieron 15.000 hombres y la totalidad de su armamento y equipo. Aquellos tres días de lucha fueron también la última intervención masiva de las unidades a caballo, cuyas cargas y galopadas por el valle del Alfambra pusieron término a una tradición milenaria ${ }^{27}$.

La derrota forzó a Rojo a abandonar la ofensiva extremeńa y Franco puso en marcha otra amplia maniobra de envolvimiento que condujo a la definitiva pérdida de Teruel. Esta batalla, la más propagandística y sangrienta de la guerra, causó un grave quebranto al Ejército Popular, cuyo armamento y material sufrieron importantes dańos, y provocó el desplome de la moral de su retaguardia. Y no fueron menores sus repercusiones políticas, estando en el origen del cese de Prieto como ministro de Defensa y la absorción de esta cartera por Negrín.

26. José Manuel Martínez Bande, La batalla de Teruel, Madrid, San Martín, 1974.

27. Rafael García-Valiño, Guerra de Liberación española: campañas de Aragón y Maestrazgo, batalla de Teruel, batalla del Ebro, Madrid, Biosca, 1949, p. 195 y 196. 
Nada más tomar Teruel, Franco decidió explotar el éxito en los campos aragoneses. Para ello disponía de más de 150.000 hombres, 750 cañones y 600 aviones, que incluían por primera vez Junkers-87 y Stukas, futuros protagonistas de la II Guerra Mundial. Enfrente tenía 100.000 soldados, apoyados por 500 piezas de artillería y 250 aviones, aunque tanto las unidades como el material estaban muy quebrantados. La importancia de las fuerzas en presencia ponía de relieve la importancia que ambos bandos prestaban ya al teatro de operaciones aragonés.

Rojo, sin calibrar adecuadamente a su oponente, estimó que daría un respiro a unos hombres que llevaban dos meses combatiendo bajo durísimas condiciones climáticas y que pasaría algún tiempo antes de emprender una nueva acción. Su errónea estimación contribuyó notablemente al desastre que se le vino encima a la República, pues Franco, sólo quince días después de tomar Teruel, inició la espectacular maniobra que le habría de llevar a orillas del Mediterráneo, dejando aislada Cataluña ${ }^{28}$.

Lo que despistó a Rojo fue olvidar la obsesión de Franco por recuperar cualquier terreno que hubiera estado en sus manos. Debido a ello, en lugar de iniciar la explotación del éxito desde las posiciones alcanzadas, como rezaban los manuales, decidió recuperar Belchite. A tal objeto, trasladó sus tropas al sur de Zaragoza y, el 9 de marzo, las lanzó en tromba hacia dicha población y el cuerpo de ejército allí situado se disolvió como un azucarillo ${ }^{29}$. Los carros alemanes, al tomar conciencia de la ausencia de enemigo a su frente, avanzaron espectacularmente por la llanura sur del Ebro, presagiando la blitzkrieg de la II Guerra Mundial ${ }^{30}$. Rojo se trasladó a Alcañíz, donde pudo advertir el desastre que se avecinaba al no lograr localizar ninguna de las unidades que en teoría se venían replegando hacia ese punto. Convertido en el Guernica de la aviación italiana, fue ocupado el día $14^{31}$.

En apenas una semana, se había perdido una franja de terreno de 100 kilómetros de profundidad por 150 de frente. Rojo decidió asumir directamente el mando y defender a ultranza la margen derecha del río Guadalope, que resistió bien los embates del enemigo, más preocupado durante las siguientes jornadas en hacerse con Caspe, defendido por brigadistas internacionales, que cayó en sus manos el día 17.

Alcanzada dicha línea, Franco dio por finalizada la primera fase de la ofensiva que acabaría en el Mediterráneo, pero su indiscutible triunfo le movió a realizar una segunda maniobra de explotación del éxito al norte del Ebro, que le llevase al valle del Segre, evitara cualquier posible ataque de flanco sobre el terreno conquistado al sur del río y le proporcionase una base de partida para atacar Cataluña.

28. José Manuel Martínez Bande, La llegada al mar, Madrid, San Martín, 1975.

29. Rojo, op. cit., p. 135.

30. Antonio Cordón, Trayectoria: memorias de un militar republicano, Barcelona, Crítica, 1977 , p. 318 y 319.

31. José María Maldonado, Alcañiz 1938: el bombardeo olvidado, Zaragoza, Ibercaja, 2003. 
Solo cuatro divisiones republicanas defendían aquel extenso territorio, mermadas de efectivos y sin apenas armamento pesado. No obstante, Franco quiso asegurarse el triunfo y decidió cruzar el Ebro para amenazar la retaguardia enemiga. Rojo, más atento a la ortodoxia de los reglamentos que a las verdaderas intenciones del adversario, desestimó las noticias que auguraban la inminencia de otro ataque por Huesca.

El 22 de marzo, de forma simultánea, se rompió este frente y los franquistas se apoderaron de las sierras prepirenaicas, cortaron la carretera de Huesca a Zaragoza, y vadearon el Ebro por Quinto. Rojo restó importancia a lo ocurrido en Huesca y retiró fuerzas de aquel frente para repeler el previsible avance hacia Lérida. El 24 todo el frente aragonés se derrumbó y Huesca quedó embolsada. Rojo advirtió finalmente la dimensión de la ofensiva y, al tomar conciencia del peligro que se cernía sobre Cataluña, resolvió reforzar Lérida y contraatacar desde Alcañiz. Sin embargo, ya era demasiado tarde; los medios de transporte, en pésimo estado tras las jornadas de Teruel, eran insuficientes para tal desplazamiento de efectivos y no resultaba fácil articular grandes unidades en tan poco tiempo.

El cataclismo sufrido se saldó con la dimisión de Prieto y, en el frente, los franquistas lograron traspasar el Cinca, muy crecido por la apertura de las compuertas de sus embalses, y llegaron a la margen del Segre. Rojo, al que Negrín confirmó en su puesto, comenzó a poner orden en aquel caos y, con un aluvión de unidades traídas de otros frentes, constituyó un nuevo cuerpo de ejército que impidió la invasión de Cataluña, pero no la pérdida de Lérida.

La abrumadora derrota republicana proporcionó a Franco 15.000 kilómetros cuadrados, superficie aún mayor que la obtenida al sur del Ebro, con la repercusión política de la pérdida de una de las capitales catalanas y el perjuicio económico de privar a su industria de la energía procedente de las centrales hidroeléctricas pirenaicas. La batalla se saldó con una cifra relativamente baja de muertos y heridos, pero cayeron en manos Franco miles de prisioneros y un inmenso botín de guerra, parte del cual acababa de llegar de la Unión Soviética.

A finales de marzo y principios de abril se combatía simultáneamente en todo el frente aragonés, desde los Pirineos al Maestrazgo. Por las mismas fechas en que se perdía Lérida, se reinició al sur del Ebro la segunda fase de la explotación del éxito que llevaría a los franquistas a orillas del Mediterráneo. Para evitarlo, la República contaba con dos cuerpos de ejército, bien pertrechados de moderno material soviético. Sin embargo, una vez más, el enemigo se impuso y su vertiginoso avance presagiaba la inminente escisión del territorio republicano. Dándolo por descontado, Negrín ordenó que se conservaran expeditos los puentes del Ebro en Tortosa, para trasladar a Cataluña cuantas unidades pudieran recuperarse de la zona amenazada. Esta decisión muestra la angustia que vivía Barcelona, cuya población sufría continuos bombardeos aéreos. Unos 25.000 hombres lograron traspasar el Ebro para reorganizarse en Cataluña, pero la magnitud del desastre queda patente al ver que sólo se salvaron 121 piezas de artillería de las 350 disponibles a comienzos de marzo. 
En apenas un mes, Franco había conquistado 6.400 kilómetros cuadrados y se había hecho con un cuantioso botín, pero sobre todo con 70 kilómetros de costa, con algunos pequeños fondeaderos de suma utilidad para su flota, y había dejado aislada Cataluña, donde radicaba el grueso del tejido industrial republicano y albergaba la única frontera internacional por donde podía recibirse ayuda.

\section{La ofensiva sobre Valencia y la batalla del Ebro}

Todo presagiaba que Franco iba a invadir Cataluña. Pese a las muchas hipótesis barajadas, seguramente nunca se sabrá por qué no lo hizo. La realidad fue que ordenó marchar a las tropas que defendían Teruel a Sagunto, hacia donde también se dirigirían las que habían llegado al Mediterráneo, para caer después ambas sobre Valencia ${ }^{32}$.

Simultáneamente, Negrín tomó la decisión de crear dos grupos de ejércitos: el de la Región Central (GERC), constituido por los cinco ejércitos que habían quedado fuera de Cataluña, y el de la Región Oriental (GERO), con las unidades que habían logrado cruzar el Ebro. Negrín, auxiliado por Rojo, se atribuyó el mando del GERO y delegó en Miaja el del GERC.

El abrupto terreno del Maestrazgo, la afluencia de efectivos del GERC y las potentes líneas fortificadas erigidas al norte de Valencia demoraron el avance franquista y, a finales de julio, cuando se inició la batalla del Ebro, no habían llegado a Castellón.

La batalla del Ebro obedeció a un violento choque de voluntades. De una parte, la tenaz voluntad de vencer de Negrín, que logró revitalizar los despojos de su ejército, insuflarle moral de victoria y rearmarlo suficientemente. Y de otra, la obsesión de Franco por triturar de una vez a un enemigo que parecía renacer una y otra vez de sus cenizas ${ }^{33}$.

El objetivo era reunificar la zona republicana. Como en Teruel, el teatro de operaciones carecía de valor estratégico. Su elección correspondió en exclusiva a Negrín, que optó por una zona fácilmente controlable desde Barcelona. El terreno elegido fue la comarca denominada Terra Alta, un anfiteatro montańoso al otro lado del Ebro sin tejido industrial de importancia ${ }^{34}$.

Negrín encomendó la tarea a las tropas de Modesto: unos 100.000 hombres bastante bien pertrechados, pero con pocos cañones, aviones y vehículos blindados. Frente a ellos, los 40.000 del Cuerpo de Ejército Marroquí, mandado por Yagüe.

Rojo concibió tres acciones ofensivas complementarias: una de distracción por la parte de Lérida; la principal, consistente en cruzar el Ebro para establecer

32. José Manuel Martínez Bande, La ofensiva sobre Valencia, Madrid, San Martín, 1977.

33. Miguel Alonso Baquer, El Ebro: la batalla decisiva de los cien días, Madrid, La Esfera de los Libros, 2003, p. 29 y 30.

34. José Manuel Martínez Bande, La batalla del Ebro, Madrid, San Martín, 1978. 
una amplia cabeza de puente frente a Gandesa y avanzar en dirección a Valencia, $\mathrm{y}$ otras dos secundarias en Mequinenza y Amposta, destinadas a desorientar al enemigo ${ }^{35}$.

El cruce del Ebro se realizaría por varios puntos, de noche y por sorpresa, para lo cual, con sumo sigilo, se comenzó a instruir a las tropas en la difícil operación de paso de ríos en las playas tarraconenses. La industria catalana fabricó pasarelas, puentes flotantes, puentes pesados y compuertas para prevenir riadas, que sumados a las barcas requisadas en los pueblos del litoral, permitían una capacidad de transporte de 8.000 hombres a la hora ${ }^{36}$.

Yagüe menospreció los continuos informes que indicaban una inusual actividad del enemigo, incluso horas antes de que, a medianoche del 25 de julio, comenzase el cruce del río. La entrada en acción de su reserva no detuvo a los republicanos, ni tampoco la intervención de la Legión Cóndor cuando amaneció.

Al finalizar el día, se habían alcanzado dos objetivos. Uno estratégico -la interrupción de la ofensiva contra Valencia-, y otro táctico, la ocupación con muy escasas bajas de dos importantes cabezas de puente en Gandesa y Mequinenza. La llegada de refuerzos y los impunes bombardeos aéreos en los puntos de paso, unidos a la apertura de los embalses, paralizaron la ofensiva, sin lograrse por tanto reunificar el territorio republicano. La lucha por la posesión de Gandesa fue una verdadera lucha de titanes y, tras seis días de violentos combates, Modesto abandonó la partida y ordenó pasar a la defensiva.

Negrín debería haber abandonado aquel baldío terreno en el momento en que fracasó la proyectada reunificación. Tampoco era lógico que Franco se empecinase en reconquistarlo y sus generales le recomendaron reiniciar la operación sobre Valencia o lanzarse contra Barcelona desde Lérida. Pero al considerar Negrín una cuestión de prestigio no abandonar lo conquistado y obstinarse Franco en recuperar lo perdido, los objetivos propagandísticos se antepusieron a los bélicos y la batalla se convirtió en una carnicería sin sentido, en la que los republicanos llevaban las de perder al carecer de suficiente artillería y no dominar el aire.

Durante los tres meses siguientes y en tres fases sucesivas, los franquistas lanzaron potentes y sangrientos contraataques que acabaron doblegando la enconada resistencia republicana. No obstante, su retaguardia, habituada a los triunfos, comenzó a clamar por poner fin a la guerra ${ }^{37}$. Tampoco en Barcelona corrían vientos muy optimistas - «De la noche a la mañana [Negrín] apareció con el rostro demudado y una delgadez alarmante» ${ }^{38}$ - y las crónicas enviadas desde el frente dejaban traslucir el desánimo y agotamiento de los combatientes y sus pésimas condiciones de vida.

35. Rojo, op. cit., p. 147-159.

36. Julio Diamante, Mis recuerdos de la Guerra Civil española, Madrid, INSERSO, 2007, p. $155-168$.

37. Juan Vigón, Cuadernos de guerra y notas de paz, Oviedo, Instituto de Estudios Asturianos, 1970, p. 284.

38. Julián Zugazagoitia, Guerra y vicisitudes de los españoles, Barcelona, Tusquets, 2001, p. 450. 
$\mathrm{Al}$ amanecer del 16 de noviembre, tras 113 jornadas de lucha, los últimos soldados republicanos cruzaron el río y dinamitaron los puentes ${ }^{39}$. Atrás, dejaban 3.000 cadáveres, 20.000 prisioneros y la mayor parte del armamento. Hacia el mediodía, llegaron a las orillas del río las primeras unidades de Franco, la batalla se dio por concluida y con ella cualquier esperanza de supervivencia de la República.

\section{La ocupación de CaTaluña y el finAl de LA GUERRA}

La situación recordaba a la de finales de abril. Cataluña estaba cercada y su defensa dependía del desmoralizado GERO, falto de armamento pesado y aviación. Negrín no se amilanó y continuó exigiendo nuevos esfuerzos a sus tropas, en la esperanza de que británicos y franceses acudirían en auxilio de la República cuando estallase la guerra en Europa y Franco se pusiese al lado de Hitler. La angustiosa situación exigía preparar con urgencia alguna operación de gran alcance estratégico y propagandístico, que evitase la invasión de Cataluña. A tal efecto, Rojo puso en marcha la siempre postergada operación sobre Extremadura y otras tres acciones de alcance limitado: un golpe de mano en Málaga; otro en Córdoba, y un ataque, inspirado en la batalla de Brunete, para cortar las comunicaciones entre Madrid y Extremadura. Todas ellas terminaron fracasando, haciendo inevitable la caída de Cataluña ${ }^{40}$.

La víspera de Nochebuena, los franquistas rompieron el frente. La línea fortificada del Segre fue rebasada y las reservas republicanas quedaron aniquiladas al ser absorbidas en los combates. Tagüeña destacó en sus memorias la crítica situación a la que se había llegado ${ }^{41}$. Los catalanes dieron por perdida la guerra $\mathrm{y}$ «centenares de familias» inundaron carreteras y caminos, primer atisbo del multitudinario éxodo que llegaría a la frontera francesa un mes después ${ }^{42}$.

Los Reyes Magos trajeron a la República buenas noticias desde Extremadura, pero en Cataluña el panorama era muy sombrío. Las pérdidas territoriales carecían de importancia comparadas con la práctica destrucción del GERO. La llamada a filas de hombres de cuarenta ańos y adolescentes de dieciocho hundió del todo la moral de la retaguardia, al desmentir los triunfalistas comunicados gubernamentales.

Tarragona, a menos de 40 kilómetros del frente, corría serio peligro y Barcelona sólo se salvaría si era capaz de emular la gesta madrileńa de noviembre de $1936^{43}$. El día 7 , ante el serio peligro de verse copadas, las tropas situadas al

39. Manuel Tagüeña, Testimonio de dos guerras, Barcelona, Planeta, 2005, p. 262.

40. José Manuel Martínez Bande, La campaña de Cataluña, Madrid, San Martín, 1979.

41. Tagüeńa, op. cit., p. 275.

42. Juan Modesto, Soy del Quinto Regimiento (notas de la guerra española), París, Ebro, 1969, p. 258.

43. Enrique Líster, Nuestra guerra: aportaciones para una historia de la guerra nacional revolucionaria del pueblo español (1936-1939), París, Ebro, 1966, p. 235. 
este del Segre se replegaron y dejaron Tarragona abandonada a su suerte, siendo ocupada sin resistencia el día 15.

De las líneas fortificadas que supuestamente debían contener el avance contra Barcelona, sólo estaba en servicio un pequeño tramo. La aviación batió impunemente a las tropas en retirada e impidió los trabajos de fortificación en torno a Barcelona. Las llamadas de Negrín a convertirla en otro Madrid no hallaron eco, y menos desde que el gobierno se trasladó a Figueras. El día 24, los franquistas llegaron a las puertas de Barcelona y su guarnición abandonó la ciudad. A la mańana siguiente, se ocupó el casco urbano sin disparar un solo tiro. Cientos de quintacolumnistas se adueñaron de las calles, ondeando banderas bicolores y vitoreando a las tropas de Franco:

Mientras por una calle entraban los conquistadores, aclamados por los gritos de sus simpatizantes, por la de al lado se retiraban nuestros maltrechos hombres [...]. Muchos de nuestros soldados, e incluso oficiales, que hasta entonces habían sido magníficos combatientes, tiraban las armas y se entregaban, considerando inútil seguir adelante ${ }^{44}$.

La incruenta ocupación de Barcelona tuvo enorme repercusión dentro y fuera de Espańa, y miles de aterrados fugitivos se apelotonaron ante los pasos fronterizos, cerrados por el gobierno francés. Franco, para preservar su imagen internacional, trasladó a sus marroquíes a Andalucía e intentó cortar la retirada de los restos del Ejército Popular. Por razones humanitarias, Francia abrió los puestos fronterizos: unos 170.000 ancianos, mujeres y niños fueron dispersados por los departamentos franceses, y 45.000 hombres, concentrados en la playa de Argelès ${ }^{45}$.

El 5 de febrero, Gerona cayó en manos de Franco, el presidente Azaña se internó en Francia y Rojo recomendó evacuar las tropas a Francia. Lo que vino a continuación superó todas las previsiones del gobierno francés. Sus cálculos eran que Barcelona emularía la gesta de Madrid y que allí se detendría el avance franquista. Una vez patente su errónea estimación, consideró lógico que Negrín capitulara. Al no cumplirse tampoco este pronóstico, contempló horrorizado la llegada de miles de soldados dispuestos a cruzar la frontera, por lo que se decidió recluirles en campos de concentración, como se había hecho con los 45.000 civiles en edad militar ${ }^{46}$.

El jefe de la región militar pirenaica coordinó su evacuación con Rojo, quien, ignorante de las instrucciones que su colega había recibido y confiado en que, conforme a la costumbre, se les trasladaría a Cartagena, vía Marsella y Orán, decidió que cada división cruzase la frontera en correcta formación.

Durante nueve días, 230.000 soldados fueron cruzando la frontera bajo la estrecha supervisión de 50.000 gendarmes franceses, quienes les requisaron el armamento, formándose enormes pilas de pistolas y fusiles al borde del camino.

44. Tagüeńa, op. cit., p. 289.

45. Javier Rubio, La emigración de la Guerra Civil de 1936-1939: historia del éxodo que se produce con el fin de la II República Española, Madrid, San Martín, 1977, t. I, p. 70-73.

46. Rubio, op. cit., t. I, p. 359-366 
El desarme fue una decisión razonable, pero al ser también desarticuladas todas las unidades, desapareció cualquier atisbo de organización jerárquica y el ejército se convirtió en una informe e indisciplinada masa de hombres, conminada a emprender una penosa caminata hacia los lugares donde se había previsto internarlos.

El día 8, mientras las tropas republicanas se internaban en Francia, los franquistas tomaron Figueras; al día siguiente La Junquera, y el 10 Port Bou. Más al oeste, otras unidades comenzaron a cruzar los abruptos pasos pirenaicos y el día 13 todo el territorio catalán quedó en manos de Franco.

Aquel desastre se correspondía con una situación insostenible en la Zona Central. La falta de brazos en el campo, sumada a una pésima cosecha, resucitó el olvidado fenómeno de la hambruna, y esta vez no sólo en Madrid, que la llevaba padeciendo desde principios de la guerra, sino incluso en las hasta entonces bien alimentadas provincias levantinas. En contraste, la zona gobernada por Franco vibraba de entusiasmo, contemplaba alborozada la proximidad de la victoria y, pese a la mala cosecha, los mercados estaban bien surtidos.

El 27 de febrero, Francia y el Reino Unido establecieron relaciones diplomáticas con Franco. Azaña dimitió y, amparado en el criterio de Rojo, aconsejó a Negrín que gestionase una paz humanitaria. Este desestimó el consejo y decidió desembarazarse de los militares profesionales y conceder el mando de los diferentes ejércitos a hombres estrechamente vinculados con el Partido Comunista, partidario de prolongar la guerra. Ante esta tesitura, Miaja y el general Casado, jefe del Ejército del Centro, acordaron hacerse con el poder y negociar la capitulación. A medianoche del 5 de marzo, Julián Besteiro formó un Consejo Nacional de Defensa, cuya presidencia asumió Miaja, constituido por Casado en Defensa y por representantes de todas las organizaciones políticas y sindicales del Frente Popular, a excepción del Partido Comunista.

Nada más amanecer, varias unidades mandadas por comunistas entraron en Madrid para tratar de neutralizar el golpe de estado, lo que provocó una guerra civil en miniatura, que se saldó con cientos de muertos y, al entremezclarse con la rebelión de la base naval de Cartagena, con la pérdida de la flota. Aquella misma tarde, Negrín, varios ministros y los altos mandos de filiación comunista optaron por exiliarse.

Madrid vivió durante seis días una situación caótica, que cortocircuito las negociaciones abiertas con Franco. Este exigió la rendición incondicional y el día 25, ante los reparos del Consejo de Defensa, rompió las negociaciones y dio orden de avanzar en todos los frentes. Los soldados republicanos no se opusieron al avance, e incluso en bastantes lugares compartieron botas de vino y canciones de guerra para celebrar que la guerra llegaba a su término. Tan espontáneos brotes de fraternidad hicieron exclamar al general Casado: «i Quiere usted nada más elocuente y más hermoso que la paz haya empezado por abajo! ${ }^{47}$. 
Lamentablemente, las autoridades franquistas no suscribieron aquel esperanzador anhelo de pacífica convivencia. Durante casi cuarenta años, decididas a no olvidar ni perdonar, mantuvieron vivo el clima bélico, sin parecer advertir que la inmensa mayoría de la población, tanto la que había combatido como sus hijos, había asumido y sintonizado plenamente con el ambiente vivido en las trincheras en los tres últimos días de la guerra. 